COST Action FP1202

"Strengthening conservation: a key issue for adaptation of marginal/peripheral populations of forest trees to climate change in Europe (MaP-FGR)"

Guest Editors: Fulvio Ducci, Kevin Donnelly

\title{
Genetic diversity of core vs. peripheral Norway spruce native populations at a local scale in Slovenia
}

\author{
Marjana Westergren, \\ Gregor Bozic, \\ Hojka Kraigher
}

\begin{abstract}
We investigated the levels of genetic diversity and population differentiation among core and peripheral populations of Norway spruce along an altitudinal gradient (from inversions to upper tree line) using isoenzymes (ISO) and nuclear simple-sequence repeats (SSR) markers on overlapping set of populations. Twenty-seven to seventy trees from 11 and 7 populations were genotyped with isoenzymes and SSRs, respectively. The results partially conform to the expectations of the central-peripheral hypothesis $(\mathrm{CPH})$ and are consistent for both marker sets. Genetic differentiation among peripheral populations was low but significantly different from zero $\left(F_{\text {ST-ISO }}=0.013, F_{\text {ST-SSR }}=0.009\right)$ and higher than that among core populations $\left(F_{\text {ST-ISO }}=0.007, F_{\text {ST-SSR }}=0.005\right)$, conforming to central peripheral hypothesis. Contrastingly, levels of genetic diversity assessed by both richness and equitability measures did not significantly differ between peripheral and core populations $\left(A_{R-1 S O}=2.20\right.$ vs. $2.14, A_{R-S S R}=$ 17.16 vs. $17.68, H_{E-I S O}=0.183$ vs. 0.185 , and $H_{E-S S R}=0.935$ vs. 0.935 for peripheral and core populations, respectively).
\end{abstract}

Keywords: Central Peripheral Hypothesis, Picea abies (L.) Karst., Genetic Diversity, Genetic Differentiation, Upper Tree Line, Inversion

\begin{abstract}
Introduction
Norway spruce (Picea abies [L.] Karst.) is among the most important conifer tree species in Europe and in Slovenia. It can grow on diverse sites, and often forms continuous stands, either alone or in mixtures (Skrøppa 2003). In general, it exhibits high levels of genetic variability within populations and low levels of differentiation (Langercrantz \& Ryman 1990, Müller-Starck 1995, Vendramin et al. 1999, Sperisen et al. 2001, Scotti et al. 2006, Meloni et al. 2007).

Still, the central-peripheral population hypothesis (CPH) of Mayr (1963) and the extension of the abundant center model to population size and gene flow (Eckert et al. 2008) predict that peripheral populations (i.e., populations at the range limits) would have reduced genetic diversity and increased genetic differentiation, as compared to core populations (i.e., those from
\end{abstract}

the inner part of the species' range), due to supposedly lower effective population size, higher genetic drift, founder effect and isolation, or a combination of these factors.

This hypothesis has been formerly investigated in many plant and animal species. As for plants, a reduced within-population genetic diversity towards periphery of the species' range has been found in $64.2 \%$ and increased differentiation in $70.3 \%$ of the studies, as reviewed by Eckert et al. (2008), thus supporting the $\mathrm{CPH}$. Also for forest trees, empirical support of $\mathrm{CPH}$ varies across studies. For example, range-wide diversity and differentiation are consistent with CPH for Thuja occidentalis (Pandey \& Rajora 2012) and Pinus contorta (Fazekas \& Yeh 2001), but not for Pinus strobus (Rajora et al. 1998) and Liriodendron chinense (Yang et al. 2016). On the other hand, a

Slovenian Forestry Institute, Vecna pot 2, SI-1000 Ljubljana (Slovenia)

@ Marjana Westergren (marjana.westergren@gozdis.si)

Received: Mar 27, 2017 - Accepted: Jan 16, 2018

Citation: Westergren M, Bozic G, Kraigher H (2018). Genetic diversity of core vs. peripheral Norway spruce native populations at a local scale in Slovenia. iForest 11: 104-110. - doi: 10.3832/ifor2444-011 [online 2018-01-31]

Communicated by: Fulvio Ducci

(c) SISEF http: //www.sisef.it/iforest/ simulation study considering the effect of the interaction between migration, genetic drift, and time of population establishment on genetic diversity of peripheral vs. core populations, found that the pattern of genetic diversity of passive dispersers such as trees is not expected to conform to $\mathrm{CPH}$ (Dai \& Fu 2011).

Looking at vertical gradients, genetic diversity varies following four distinct patterns, one of them being concordant with CPH (Ohsawa \& Ide 2008). However, only 11 out of the 42 studies on forest trees reviewed by Ohsawa \& Ide (2008) were consistent with the expectation of highest diversity in the core (i.e., the vertical center of the gradient) and lower diversity at periphery (i.e., the distal ends of the gradient), while $53 \%$ of studies exhibit higher or equal genetic diversity at the upper range periphery than in the gradient center (core). This is important as populations at the upper range periphery are expected to colonize higher elevation sites in response to climate change (Fady et al. 2016).

Here, we contribute empirical knowledge to the debate on patterns of genetic diversity and differentiation between core and peripheral populations of Norway spruce. The studied populations are located in a small area at the upper tree line or in Karst sinkholes with vegetation inversion, which includes two distinct cases of vertical periphery. We employed richness and equitability measures based on isoenzyme and 
nuclear SSR markers to test $\mathrm{CPH}$ along an elevation gradient.

Genetic richness is a measure of the total amount of diversity which is more sensitive to the presence of rare alleles, and it is likely reduced by the stochastic processes occurring at the upper range limits (e.g., bottlenecks, fluctuations in population size). Contrastingly, equitability is more sensitive to high-frequency alleles and reflects how the diversity is partitioned among sites (Concord et al. 2012, Eckert et al. 2008).

Periphery may or may not represent ecological marginality or vice versa (Fady et al. 2016). Different habitats of peripheral Norway spruce populations at the upper tree line in the Alps may have favored specific genetic characteristics (Bergmann 1991, Holzer 1985, Bozic 2002). Therefore, we also explored the correlation of genetic diversity estimates to environmental factors using the isoenzyme dataset.

\section{Materials and methods}

\section{Study sites and field sampling}

Dormant buds of vital trees $>30 \mathrm{~m}$ apart and belonging to dominant and codominant crown classes were sampled from 15 distinct populations of Norway spruce in 1999, 2000 and 2005 (Tab. 1). The number of sampled trees in each population ranged from 30 to 70 . In no case, all dominant trees in a population were sampled. All sampled populations were naturally regenerated, putatively autochthonous and large enough, harboring at least 100 reproducing trees, for population size not to be a confounding factor. Natural regeneration was present at all study sites. The stand characteristics, ecological conditions and number of trees sampled are presented in Tab. 1. The location of the studied populations is reported in Fig. S1 (Supplementary material).
The sampled populations were classified as: (i) core populations, i.e., located in the core of the distribution range; or (ii) peripheral populations, growing either at the upper tree line or in a vegetation inversion. The latter is a common phenomenon in $\mathrm{Di}$ naric Karst where the landform depresses below the surrounding area and the temperature decreases towards the depression bottom. The temperature inversion determines an inversion of the vegetation belts, whereby beech forests grow on the hilltop, followed by Norway spruce stands, and dwarf pine and other small shrubs at the bottom (see Fig. S2 in Supplementary material).

\section{Isoenzyme analysis}

Enzyme extraction from dormant buds was performed according to Rhodes (1977). Electrophoresis conditions, staining, and genotyping followed Konnert \& Maurer (1995). The laboratory part of the analysis was carried out at the Bayerische Amt für forstliche Saat und Pflanzenzucht in Teisendorf, Germany. Overall, 9 enzyme systems yielding 15 coding gene loci were analyzed (E.C. Code, loci: 2.6.1.1, Aat-A, AatB, Aat-C; 1.1.1.42, Idh-A, Idh-B; 1.1.1.37, MdhA, Mdh-B, Mdh-C; 1.4.1.2, Gdh-A; 3.4.11.1, Lap$B ;$ 5.3.1.9, Pgi-B; 2.7.5.1, Pgm-A; 1.1.1.25, Skdh-A; 1.1.1.44, 6-Pgdh-B, 6-Pgdh-C).

\section{SSR analysis}

Total DNA was isolated from dormant buds using the DNeasy ${ }^{\oplus}$ plant kit (QIAGEN, Germany), as per the manufacturer's specifications. All samples were genotyped at 6 highly variable microsatellite loci: $\mathrm{SpAGG}_{3}$ (Pfeiffer et al. 1997); EAC1Fo4 (Scotti et al. 2002); PAAC19, PAAC3 (Scotti et al. 2000); paGB8 (Besnard et al. 2003); and PGL15 (Rajora et al. 2001). Polymerase chain reactions (PCRs) were performed as described by Westergren (2010). The sizing of the $P C R$ products was performed on an $A B I$
PRISM $310^{\oplus}$ automatic sequencer with the accompanying software Gene Mapper ${ }^{\oplus} \mathrm{v}$. 3.7 (Thermo Fisher Scientific Inc., Waltham, MS, USA).

\section{Data analysis}

Genetic diversity analysis was carried out separately for the isoenzyme and SSR datasets. Estimates of genetic diversity (allelic richness $\left(A_{R}\right)$, expected $\left(H_{E}\right)$ and observed $\left(\mathrm{H}_{\mathrm{O}}\right)$ heterozygosity, and inbreeding coefficient $\left(F_{15}\right)$ were calculated using the software package SpaGeDi v. 1.4 (Hardy \& Vekemans 2002). To test for significant difference in mean values of genetic diversities between peripheral and core populations, a $t$-test with Welch's modification for unequal variances between groups was calculated in R (R CoreTeam 2016). Departure of $F_{\text {Is }}$ from zero was tested using bootstrapping (10,000 permutations) in SpaGeDi. Deviations from the Hardy-Weinberg equilibrium and linkage disequilibrium between loci were tested running 10,000 permutations with the software Genepop v. 4.0 (Rousset 2008). Presence of null alleles was checked using the EM algorithm implemented in FreeNA (Chapuis \& Estoup 2007) followed by correction of the dataset to meet the estimated frequencies of each allele in each population according to the $E M$ algorithm. For the selectively neutral SSRs, the number of migrants $(\mathrm{Nm})$ was estimated based on the private allele method implemented in Genepop.

Pairwise and global $F_{S T}$ values were calculated and their significance tested using 10,000 permutations with SpaGeDi. Genetic differences between populations were also investigated using a modelbased clustering algorithm implemented in Structure v. 2.3.4 (Pritchard et al. 2000, Falush et al. 2003, Hubisz et al. 2009). To estimate the best number of distinct clusters and to average the results of the replicated runs, the CLUMPAK software (Kopel-

Tab. 1 - Main characteristics (type of periphery, selected environmental descriptors and sampling details) of the 15 Slovenian Norway spruce populations included in this study. $\left(\mathrm{T}_{\text {sum }}\right)$ : mean May-June temperature sum $\left({ }^{\circ} \mathrm{C}\right) ;\left(\mathrm{P}_{\text {sum }}\right)$ : mean May-June precipitation sum (mm); (N): number of genotyped (sampled) trees (I: isozymes; SSR: simple-sequence repeats); (Flushing): time of leaf flushing.

\begin{tabular}{lllccccc}
\hline Population & $\begin{array}{l}\text { Type of periphery } \\
\text { (if any) }\end{array}$ & Bedrock & $\begin{array}{c}\text { Elevation } \\
(\mathbf{m} \text { a.s.I.) }\end{array}$ & $\begin{array}{c}\mathbf{T}_{\text {sum }} \\
\left({ }^{\circ} \mathbf{C}\right)\end{array}$ & $\begin{array}{c}\mathbf{P}_{\text {sum }} \\
(\mathbf{m m})\end{array}$ & N & Flushing \\
\hline Lipanca (LIP) & Upper tree line & Calcareous & 1500 & 16 & 360 & 50 I, 30 SSR & $1-10$ June \\
\hline Pungart (PP) & Upper tree line & Calcareous & 1500 & 19 & 310 & 50 I & $1-10$ June \\
\hline Veža (VE) & Upper tree line & Calcareous & 1500 & 23 & 310 & 50 I & $21-31$ May \\
\hline Goteniški Snežnik (GS) & Upper tree line & Calcareous & 1300 & 23 & 290 & 51 I & $1-10$ June \\
\hline Crno jezero (CJ) & Upper tree line & Igneous & 1200 & 23 & 290 & 27 (30) SSR & $21-31$ May \\
\hline Pod Tršarjevimi rastišči (TR) & Inversion & Calcareous & 1200 & 20 & 360 & 70 I & $1-10$ June \\
\hline Smrekova Draga (SD) & Inversion & Calcareous & 1150 & 21 & 290 & 66 I, 30 SSR & $21-31$ May \\
\hline Velika Padežnica (VP) & Inversion & Calcareous & 1200 & 20 & 360 & 52 I, 28 (30) SSR & $1-10$ June \\
\hline Tonetova bajta (TB) & - & Igneous & 1150 & 29 & 340 & 50 I & $1-10$ June \\
\hline Lipniška planina (LP) & - & Igneous & 1300 & 29 & 280 & 70 I & $1-10$ June \\
\hline Ledine (LED) & - & Igneous & 1150 & 24 & 320 & 56 I & $21-31$ May \\
\hline Smrečje (SMR) & - & Calcareous & 1100 & 22 & 290 & 50 I & $21-31$ May \\
\hline Šijec (SIJ) & - & Igneous & 1200 & 20 & 360 & 30 SSR & $21-31$ May \\
\hline Jerebikovec (JER) & - & Calcareous & 800 & 20 & 360 & 30 SSR & $1-10$ June \\
\hline Pevc (PE) & - & Calcareous & 700 & 30 & 320 & 30 SSR & $11-20$ May \\
\hline
\end{tabular}


man et al. 2015) was used. The default model parameters using populations' priors were used for simulations, allowing number of populations $K$ to vary from 1 to 7 for both datasets. Each run, replicated 8 times, consisted of 400,000 burn-in iterations and 600,000 data collection iterations.

Bonferroni's corrections were applied to adjust critical values in case of multiple comparisons.

\section{Correlations of genetic diversity}

estimates to environmental factors

In Alpine conifers, precipitation, temperature and soil play a significant role in shaping genetic variation and local adaptation (Mosca et al. 2012, 2014). To understand whether genetic diversity $\left(A_{R}, H_{E}, H_{O}\right.$, ) and $F_{\text {Is }}$ correlate with environmental factors and elevation, Spearman's correlation coefficient $(\rho)$ was used. Cambium activity in temperate regions is regulated by temperature, rainfall and photoperiod, and reflects the environmental adaptivity of trees (Begum et al. 2013). Radial growth, a result of cambial activity, of Norway spruce adult trees in the Alps is affected positively by high precipitation during May-June period, while higher mean temperature under the same period had a negative effect (Schuster \& Oberhuber 2013). Therefore, we focused our environmental association analyses on mean May to June precipitation and temperature sums. Additionally, a $t$-test with Welch's modification was used to test for significant difference in mean values of genetic estimates between groups denoted by nominal variables: bedrock (calcareous and igneous), as a determinant of soil formation, and leaf flushing (21-31 May, 1-10 June). Environmental and flushing data were obtained from the Slovenian Environment Agency data layers; precipitation and temperature for the period 1981-2010 and phenology averages from the 1971-2000 data series.

\section{Results and discussion}

\section{Quality of the selected markers}

Null alleles with frequency ranging between 0.05 and 0.36 (average $=0.21$ ) were detected in all populations at the SSR locus EAC1F04. The average frequency of null alleles at the other SSR loci was much smaller. Still, seven population/locus combinations had frequency of null alleles higher than 0.15, and 11 higher than 0.10 (but lower then 0.15), accounting for half of population/locus combinations. Therefore, the whole dataset was corrected for null alleles to fit allele frequencies estimated by the EM algorithm implemented in FreeNA. All values reported for SSRs are based on this corrected dataset.

The frequencies of null alleles for isoenzymes varied between zero and 0.14 , on average 0.01 per population/locus, exceeding 0.10 in five out of 143 population/locus combinations. Therefore, they were not corrected to fit allele frequencies estimated by the EM algorithm.

For none of the pairwise loci combinations within each population the null hypothesis of independent assortment of genotypes could be rejected.

\section{Allele frequency distribution}

\section{Isoenzymes}

Out of 15 examined loci, 13 were polymorphic in at least one of the examined populations; the two non-polymorphic loci (Mdh-A, Aat-A) were excluded from further analysis. Two to seven alleles were detected for each locus, with a total of 49 alleles across all populations and loci. Twenty-four of these were rare (frequency $<0.05$ ) or absent and 24 common (frequency $\geq 0.05$ ) across all populations. Five alleles were rare in some and common in other populations, but there was no pattern in regards to peripheral and core populations. However, nine of the rare alleles (frequencies between 0.008 and 0.014 ) were found either in only peripheral (six alleles) or core (three alleles) populations, in five cases in more than two populations (Fig. 1). On the other hand, only two private alleles were found in peripheral populations (both in populations with temperature inversion) and three in core populations.

\section{SSR}

All loci were highly polymorphic, with 17 to 53 alleles for each locus, totaling 227 alleles across all populations and loci. Of these, 114 were rare (frequency $<0.05$ ) or absent and six common (frequency $\geq 0.05$ ) across all seven studied populations. Except for one rare allele at locus PAAC19 (present only in core populations) and one allele at locus PGL15 (rare in all four peripheral populations and common in all three core populations), no pattern of allele distribution between peripheral and core populations was detected.

\section{Relationships among populations}

Previous studies reported that Norway spruce in Slovenia forms two distinct demes: (i) the Alpine and the Dinaric deme, concordant with recolonization from a glacial refugia identified by Tollefsrud et al. (2008) in the Eastern Alps; and (ii) a second deme presumably located in the north $\mathrm{Di}$ naric mountains. Such evidence was not confirmed in this study (Fig. 2). The analysis of population structure revealed that all populations belong to the same deme, both using isoenzyme and SSR markers, thus excluding the effect of hidden population structure on the findings of this study.

\section{Isoenzymes}

Using our dataset based on 13 polymorphic isozyme loci, only one genetic group was identified by Bayesian clustering (Fig. 2). The lack of genetic differentiation among populations was confirmed by pair-

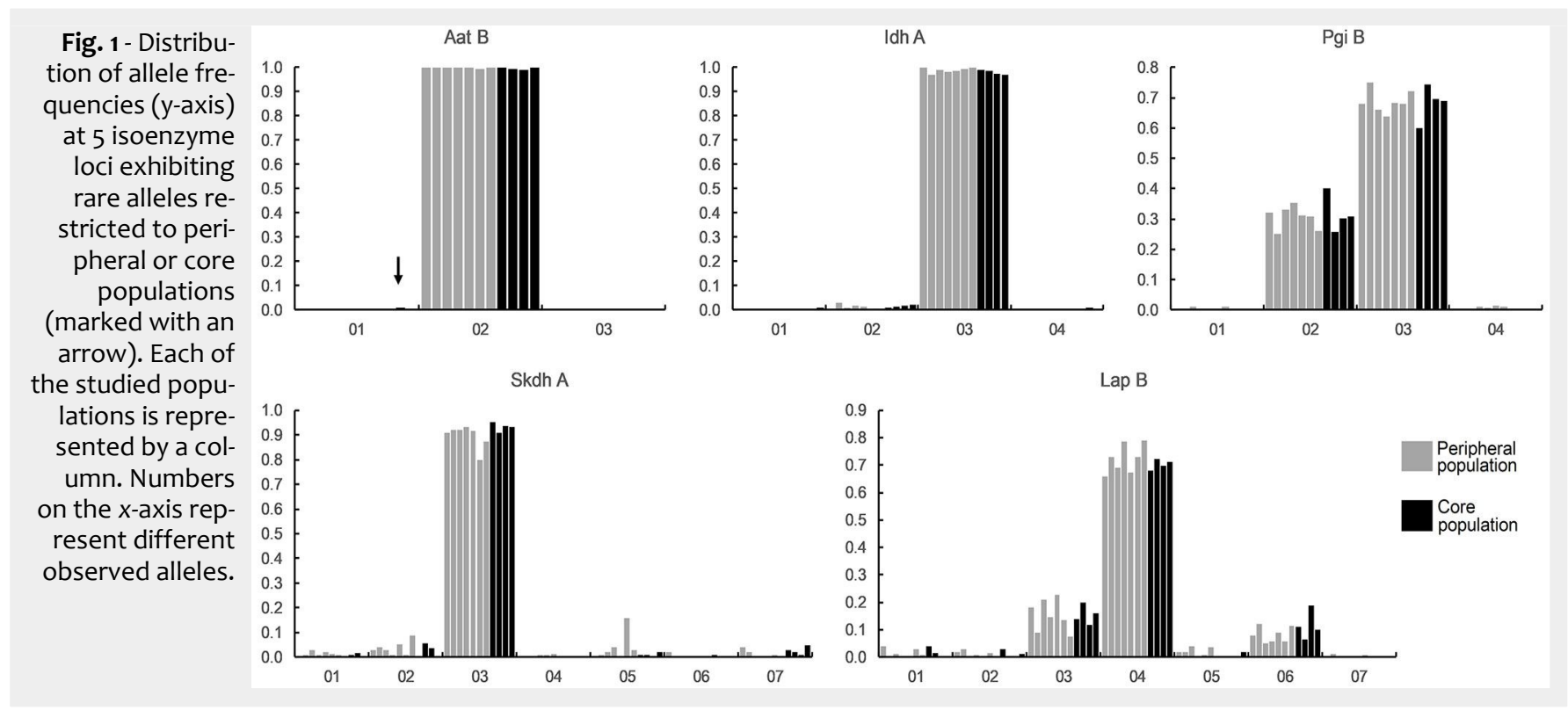



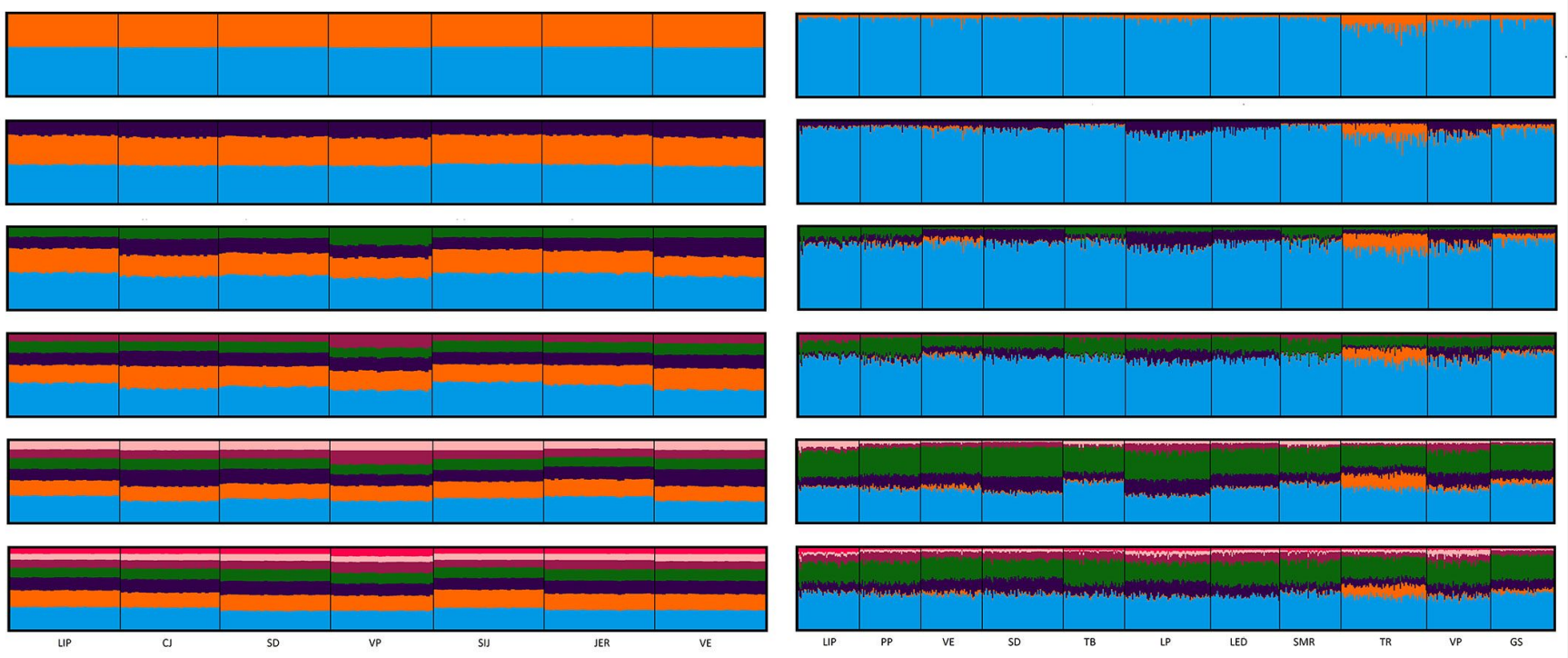

Fig. 2 - Lack of genetic structure among the analyzed populations as identified by Structure for SSR (left panel) and isoenzyme (right panel) markers. Each sampled tree is represented by a vertical line where a color denotes the part of the genome belonging to each of the $K$ clusters $(2 \leq K \leq 7)$.

wise $\mathrm{F}_{\mathrm{ST}}$ estimates between populations, which were small, ranging from 0.00 to 0.03 (Tab. S1 in Supplementary material), and were significantly different from zero (with $a=0.05$ after Bonferroni's correction) only for population pairs SD-TR (both inversion) and PP-GS (both upper tree line). Out of six pairs of populations with $\mathrm{F}_{\mathrm{ST}}$ estimates higher than 0.02 , five were pairs of peripheral populations. Population genotypic differentiation (as calculated by Genepop after the application of Bonferroni's corrections) was significant for nine population pairs; in six cases these population pairs included a peripheral population (Tab. S1). Differentiation within peripheral populations, measured as global $\mathrm{F}_{\mathrm{ST}}$, was twice as high as in core populations $\left(\mathrm{F}_{\mathrm{ST}}=\right.$ 0.007 ). Inversion populations had the highest differentiation among each other $\left(\mathrm{F}_{\mathrm{ST}}=\right.$ 0.021 - Tab. 2). Nevertheless, the $F_{S T}$ did not differ significantly between core and peripheral populations $(p=0.068)$.

\section{SSRs}

All analyzed populations belonged to the same genetic group based on the results of Bayesian clustering implemented in Structure (Fig. 2). The number of detected migrants between all populations after cor-

Tab. 2 - Genetic differentiation (global $F_{\mathrm{ST}}$ estimates) within and between core and peripheral populations and types of periphery using isoenzyme and SSR markers.

\begin{tabular}{lcccc}
\hline \multirow{2}{*}{ Population class } & \multicolumn{3}{c}{ Isoenzymes } & \multicolumn{2}{c}{ SSRS } \\
\cline { 2 - 5 } & $\mathbf{F}_{\text {ST }}$ & $\mathbf{p}$ & $\mathbf{F}_{\text {ST }}$ & $\mathbf{p}$ \\
\hline Core & 0.007 & 0.016 & 0.005 & 0.016 \\
Peripheral & 0.013 & 0.000 & 0.009 & 0.000 \\
Upper tree line & 0.012 & 0.001 & 0.009 & 0.006 \\
Inversion & 0.021 & 0.000 & 0.014 & 0.006 \\
Between upper tree line and inversion & 0.000 & 0.638 & 0.001 & 0.186 \\
Between core and peripheral & 0.002 & 0.068 & 0.002 & 0.013 \\
\hline
\end{tabular}

rection for size was moderately high, 6.6. Number of migrants estimated was slightly smaller for core $(\mathrm{Nm}=4.8)$ than for peripheral populations $(\mathrm{Nm}=6.3)$. With $\mathrm{Nm}$ being moderately high in both peripheral and core populations, ample gene flow likely counterbalances the contemporary effects of drift in the sampled populations, whereby all sampled populations seem to belong to one large panmictic population. Indeed, no differentiation was observed between core and peripheral populations using Bayesian clustering and differentiation was low for both isoenzymes and SSRs ( $F_{\text {ST-ISO }}=$ $0.002, \mathrm{~F}_{\text {ST-SSR }}=0.002$ ), although significant in the latter case $(p=0.013-$ Tab. 2$)$. High gene flow among and between core and peripheral populations may also be a consequence of the overlap in leaf phenology (Tab. 1), taken as a proxy of flowering phenology. As estimation of $\mathrm{Nm}$ based on the private alleles method assumes neutrality, and any kind of selection might lead to bias (Yamamichi \& Innan 2012), Nm was only estimated for the neutral SSRs.

Consistent with high $\mathrm{Nm}$, pairwise $\mathrm{F}_{\mathrm{ST}}$ values were mostly low and ranged from zero to 0.21 (Tab. S2 in Supplementary material). No systematic difference in differentiation between peripheral and core populations 0.068 0.002 0.013

was observed. Rather, population VP (inversion) differed significantly from all other populations except LIP (upper tree line). Of the seven significant cases of genotypic differentiation, three were among peripheral populations, three among peripheral and core populations and one among core populations (Tab. S2). Here, inversion population VP differed significantly only from the core population CV. Population VP also exhibited departure from Hardy-Weinberg equilibrium (see next section).

Despite the extensive gene flow, global $F_{S T}$ estimates significantly differed from zero in peripheral and core populations, being higher in peripheral than core populations ( $p=0.013-$ Tab. 2). Similar to the isoenzyme dataset, global $F_{\text {ST }}$ was almost twice as high in peripheral populations than in the core ones, and three times as high in inversion then in core populations.

Neither Bayesian nor classical methods revealed structuring of the studied populations using the two datasets, and gene flow was high among populations. Still, genetic differentiation was twice as high in peripheral then in core populations, in inversion populations three times as high as in core populations in both datasets. This is in concordance with the $\mathrm{CPH}$ and consistent with more than $70 \%$ of the 37 studies on plant species reviewed in Eckert et al. (2008). For forest trees, the same pattern was observed for Thuja occidentalis (Pandey \& Rajora 2012) and Pinus contorta (Fazekas \& Yeh 2001) but not in Liriodendron chinense (Yang et al. 2016) or Pinus strobus (Rajora et al. 1998).

\section{Genetic diversity estimates}

\section{Isoenzymes}

Multilocus estimates of genetic diversity, i.e., allelic richness $\left(A_{R}\right)$, observed heterozy- 
gosity $\left(\mathrm{H}_{\mathrm{O}}\right)$, expected heterozygosity $\left(\mathrm{H}_{\mathrm{E}}\right)$ and inbreeding coefficient $\left(\mathrm{F}_{\mathrm{IS}}\right)$ averaged $2.204 \pm 0.051,0.175 \pm 0.004,0.183 \pm 0.003$ and $0.043 \pm 0.024$, respectively, for peripheral populations, and $2.143 \pm 0.101,0.168 \pm$ $0.016,0.185 \pm 0.009$ and $0.092 \pm 0.055$ for core populations, respectively. The number of private alleles and $F_{15}$ were lower by $62 \%$ and $74 \%$ in peripheral than core populations. Nevertheless, the null hypothesis of equal means of peripheral and core populations could not be rejected at $\alpha=0.05$ for neither these two estimates nor any of the other estimates. Hardy-Weinberg's equilibrium was rejected for two out of 11 populations: the peripheral population VP and the core population TB. Isoenzyme diversity estimates in each population are presented in Tab. 3.

\section{SSR}

Multilocus estimates of genetic diversity, i.e., allelic richness $\left(A_{R}\right)$, observed heterozygosity $\left(\mathrm{H}_{\mathrm{O}}\right)$, expected heterozygosity $\left(\mathrm{H}_{\mathrm{E}}\right)$ and inbreeding coefficient $\left(F_{15}\right)$ averaged $17.158 \pm 0.219,0.908 \pm 0.0213,0.926 \pm 0.007$ and $0.020 \pm 0.021$, respectively, for peripheral populations and $17.680 \pm 0.624,0.924$ $\pm 0.003,0.935 \pm 0.006$ and $0.014 \pm 0.009$ for core populations, respectively. Similar to isoenzymes, the null hypothesis of equal means of peripheral and core populations could not be rejected at $\alpha=0.05$ for none of the SSR diversity estimates nor for $\mathrm{F}_{\mathrm{IS}}$, number of rare and number of private alleles. Nevertheless, average $F_{\text {Is }}$ was by $157 \%$ higher in peripheral than in core populations (Tab. 4), opposite to the pattern observed with isoenzymes. Higher $F_{i s}$ in peripheral populations was also reported for Picea sitchensis (Gapare \& Aitken 2005). Despite corrections for null alleles, the HardyWeinberg's equilibrium was rejected for population VP $(p=0.04)$. SSR diversity estimates for each population are presented in Tab. 4.

None of the datasets exhibited significant differences in genetic diversity estimates between core and peripheral populations for neither richness nor equitability measures. Moreover, neither the presence and quantity of rare nor the higher frequency alleles differed between core and peripheral populations, thereby rejecting the expectations based on the $\mathrm{CPH}$ hypothesis. Similar to Picea sitchensis (Gapare \& Aitken 2005), Pinus strobus (Rajora et al. 1998) and Liriodendron chinense (Yang et al. 2016), genetic diversity in the studied peripheral Norway spruce populations was not lower than in core populations. In contrast, core populations of Thuja occidentalis (Pandey \& Rajora 2012) had higher diversity of richness measures. Still, the same study revealed similar expected heterozygosity in both core and peripheral populations, as found in our study.

\section{Genetic diversity in relation to} environmental factors

Correlation analysis was carried out on
Tab. 3 - Estimates of within-population genetic diversity, rare and private alleles for the 11 populations analyzed with isoenzyme makers. $\left(A_{R}\right)$ : mean number of alleles per locus standardized to the smallest sample size of 100 gene copies; $\left(\mathrm{N}_{\text {RARE }}\right)$ : number of rare alleles (freq. $<0.05)$ in a population; $\left(\mathrm{N}_{\text {PRIV }}\right)$ : number of private alleles; $\left(\mathrm{H}_{\mathrm{E}}\right)$ : expected heterozygosity; $\left(\mathrm{H}_{\mathrm{O}}\right)$ : observed heterozygosity; $\left(\mathrm{F}_{\mathrm{IS}}\right)$ : mean inbreeding coefficient; (UTL): upper tree line; (INV): inversion; (PERIP): peripheral; (CORE): core population; $(*): p<0.05$. For population codes, see Tab. 1.

\begin{tabular}{llcccccc}
\hline Population & $\begin{array}{l}\text { Periphery } \\
\text { type }\end{array}$ & $\mathrm{A}_{\mathrm{R}}$ & $\mathrm{N}_{\text {RARE }}$ & $\mathrm{N}_{\text {PRIV }}$ & $\mathrm{H}_{\mathrm{E}}$ & $\mathrm{H}_{\mathrm{O}}$ & $\mathrm{F}_{\text {IS }}$ \\
\hline LIP & UTL & 2.20 & 11 & 0 & 0.184 & 0.179 & 0.027 \\
PP & UTL & 2.20 & 12 & 0 & 0.181 & 0.184 & -0.016 \\
VE & UTL & 2.13 & 11 & 0 & 0.185 & 0.179 & 0.037 \\
GS & UTL & 2.06 & 9 & 0 & 0.168 & 0.174 & -0.033 \\
TR & INV & 2.39 & 15 & 1 & 0.188 & 0.175 & 0.068 \\
VP & INV & 2.38 & 12 & 1 & 0.181 & 0.153 & $0.159^{*}$ \\
SD & INV & 2.07 & 9 & 0 & 0.193 & 0.182 & 0.061 \\
TB & CORE & 2.00 & 8 & 0 & 0.178 & 0.143 & $0.2^{*}$ \\
LP & CORE & 2.34 & 14 & 0 & 0.202 & 0.194 & 0.037 \\
LED & CORE & 2.10 & 9 & 2 & 0.185 & 0.179 & 0.033 \\
SMR & CORE & 2.13 & 10 & 1 & 0.174 & 0.157 & 0.099 \\
\hline Means & UTL & 2.15 & 10.75 & 0 & 0.180 & 0.179 & 0.004 \\
& INV & 2.28 & 12 & 0.67 & 0.187 & 0.170 & 0.096 \\
& PERIP & 2.20 & 11.29 & 0.29 & 0.183 & 0.175 & 0.024 \\
& CORE & 2.14 & 10.25 & 0.75 & 0.185 & 0.168 & 0.092 \\
Change (\%) & UTL Vs. CORE & +0.22 & +4.88 & -100.00 & -2.73 & +6.39 & -95.94 \\
& INV vs. CORE & +6.42 & +17.07 & -11.11 & +1.51 & +1.04 & +4.07 \\
& PERIP Vs. CORE & +3.00 & +10.10 & -61.90 & -1.16 & +4.25 & -73.91 \\
Pooled & UTL & 3.11 & 21 & 0 & 0.209 & 0.206 & 0.014 \\
samples & INV & 3.08 & 19 & 2 & 0.220 & 0.198 & $0.102^{*}$ \\
& CORE & 3.22 & 23 & 4 & 0.216 & 0.197 & $0.088^{*}$ \\
\hline
\end{tabular}

the isoenzyme dataset. The only significant 0.104$)$, while no pattern was observed becorrelation was found between $F_{15}$ and ele- tween $A_{R}$ and precipitation $(\rho=0.345, p=$ vation ( $\rho=0.637, p=0.035$ - Fig. 3 ); the 0.299 ) nor among other genetic and envipopulations from lower elevations showed ronmental indices. Mean values of genetic higher $F_{15}$ than populations from higher ele- diversities $A_{R}, H_{E}, H_{O}$ and $F_{I S}$ did not differ vations. Temperature and $A_{R}$ tended to- significantly neither between populations wards a negative correlation $(\rho=-0.516, p=$ growing on different bedrock nor for pop-

Tab. 4 - Estimates of within-population genetic diversity, rare and private alleles for the 7 populations analyzed with SSR markers. $\left(A_{R}\right)$ : mean number of alleles per locus standardized to the smallest sample size of 54 gene copies; $\left(\mathrm{N}_{\mathrm{RARE}}\right)$ : number of rare alleles (freq. $<0.05)$ in a population; $\left(\mathrm{N}_{\mathrm{PRIV}}\right)$ : number of private alleles; $\left(\mathrm{H}_{\mathrm{E}}\right)$ : expected heterozygosity; $\left(\mathrm{H}_{\mathrm{O}}\right)$ : observed heterozygosity; $\left(\mathrm{F}_{\mathrm{IS}}\right)$ : mean inbreeding coefficient; (UTL): upper tree line; (INV): inversion; (PERIP): peripheral; (CORE): core population; (*): $\mathrm{p}<0.05$. For population codes, see Tab. 1.

\begin{tabular}{llcccccc}
\hline Population & $\begin{array}{l}\text { Periphery } \\
\text { type }\end{array}$ & $\mathrm{A}_{\mathrm{R}}$ & $\mathrm{N}_{\text {RARE }}$ & $\mathrm{N}_{\text {PRIV }}$ & $\mathrm{H}_{\mathrm{E}}$ & $\mathrm{H}_{\mathrm{O}}$ & $\mathrm{F}_{\text {IS }}$ \\
\hline LIP & UTL & 17.61 & 67 & 7 & 0.936 & 0.882 & 0.060 \\
CJ & UTL & 17.07 & 56 & 6 & 0.928 & 0.939 & 0.014 \\
SD & INV & 17.36 & 71 & 7 & 0.934 & 0.950 & 0.018 \\
VP & INV & 16.59 & 63 & 10 & 0.906 & 0.862 & 0.052 \\
SIJ & CORE & 18.62 & 73 & 9 & 0.944 & 0.918 & 0.030 \\
JER & CORE & 17.92 & 87 & 8 & 0.936 & 0.926 & 0.012 \\
CV & CORE & 16.5 & 75 & 6 & 0.925 & 0.927 & 0.001 \\
\hline Means & UTL & 17.34 & 62.50 & 6.50 & 0.932 & 0.911 & 0.037 \\
& INV & 16.98 & 67.00 & 8.50 & 0.920 & 0.906 & 0.035 \\
& PERIP & 17.16 & 64.25 & 7.70 & 0.935 & 0.924 & 0.036 \\
& CORE & 17.68 & 78.33 & 7.67 & 0.935 & 0.924 & 0.014 \\
Change (\%) & UTL VS. CORE & -1.92 & -20.51 & -15.58 & -0.29 & -1.43 & +68.29 \\
& INV VS. CORE & -3.96 & -14.10 & +10.39 & -1.57 & -1.91 & +24.39 \\
& PERIP vs. CORE & -2.96 & -17.63 & -2.06 & -0.96 & -1.70 & +157.14 \\
Pooled & UTL & 16.97 & 107 & 13 & 25.460 & 0.936 & $0.919^{*}$ \\
samples & INV & 15.72 & 117 & 18 & 25.560 & 0.929 & $0.910^{*}$ \\
& CORE & 17.49 & 149 & 28 & 26.110 & 0.938 & $0.928^{*}$ \\
\hline
\end{tabular}


Fig. 3 - Plot of $F_{\text {Is }}$ estimates vs. elevation.

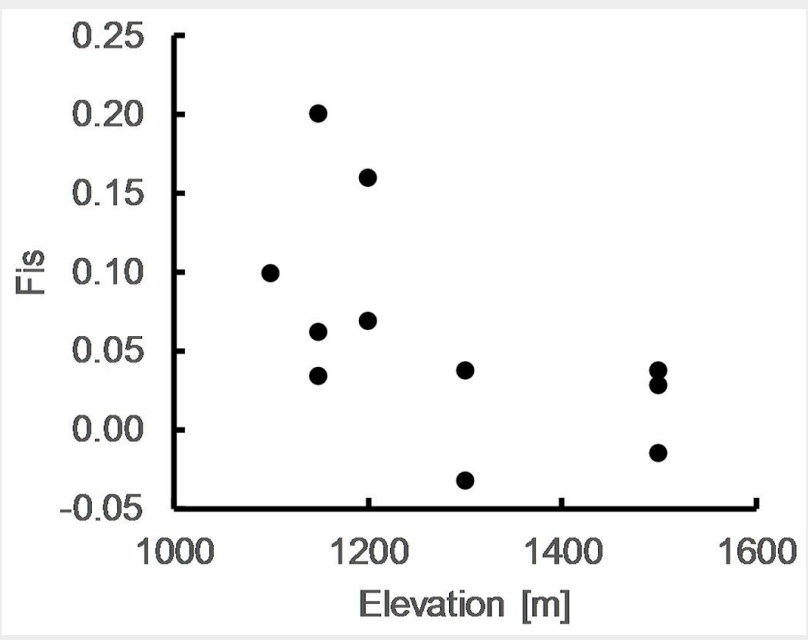

ulations with different start of leaf flushing.

\section{Conclusions}

Our study was based on a limited number of populations from a geographically restricted area in the center of distribution of the southern lineage of Norway spruce in Slovenia. The studied populations were classified as core and peripheral, i.e., growing at the range margins (upper tree line, inversion). The added value of the study is: (i) the comparison of populations growing in a geographic area much smaller then those of similar studies carried out so far, therefore giving insights on the conformity to $\mathrm{CPH}$ over small distances; (ii) addressing periphery along an altitudinal gradient; and (iii) comparing the results based on two types of markers.

Our results showed that differentiation is higher in peripheral populations according to predictions from $\mathrm{CPH}$, while genetic diversity is similar in peripheral and core populations. Moreover, the number of private and rare alleles were similar among core and peripheral populations (the number of private alleles in the isoenzyme dataset was much lower in peripheral populations, though not significantly different). This supports the evidence that peripheral populations along an altitudinal gradient may harbor alleles valuable for future adaptation (Fady et al. 2016).

The studied populations are geographically close to each other or close to other Norway spruce populations. Therefore, a high gene flow among populations is not surprising given the biology of the species. Higher differentiation of peripheral populations at the upper tree line and in inversions might be the result of lower effective population sizes and shorter lifespan at higher altitudes (Sakai et al. 2003) or presumably at the bottom of vegetation inversions, leading to faster adaptation and consecutively, differentiation.

\section{Acknowledgements}

This study was done within the framework of research tasks of projects: $V_{4}-1438$,
V4-1614, COST Action FP1202 Strengthening conservation: a key issue for adaptation of marginal/peripheral populations of forest trees to climate change in Europe (MaPFGR), and the Research Programme P40107 financed by the Slovenian Research Agency, V4-1438 and V4-1614 co-financed by the Ministry for Agriculture, Forestry and Food of the Republic of Slovenia. The authors are grateful to Dr. Monika Konnert (ASP, Teisendorf, Germany) for her supervision in the isoenzyme analysis. Data visualization was aided by Daniel's XL Toolbox Add-in for Excel, version 6.52 , by Daniel Kraus, Würzburg, Germany.

\section{References}

Begum S, Nakaba S, Yamagishi Y, Oribe Y, Funada $R$ (2013). Regulation of cambial activity in relation to environmental conditions: understanding the role of temperature in wood formation of trees. Physiologia Plantarum 147: 4654. - doi: 10.1111/j.1399-3054.2012.01663.x

Bergmann F (1991). Causes and consequences of species-specific genetic variation patterns in European forest tree species: Example of Norway spruce and silver fir. In: "Genetic variation in European populations of forest trees" (Müller-Starck G, Ziehe M eds). J. D. Sauerländers Verlag, Frankfurt am Main, Germany, pp. 192240.

Besnard G, Acheré V, Faivre Rampant P, Favre JM, Jeandroz S (2003). A set of cross-species amplifying microsatellite markers developed from DNA sequence databanks in Picea (Pinaceae). Molecular Ecology 3: 380-383. - doi: 10.1046/j.1471-8286.2003.00456.x

Bozic G (2002). Subpopulation differentiation under different forest site conditions within autochthonous Norway spruce (Picea abies (L.) Karst.) population. The Slovenian Academy of Sciences and Arts - Razprave 3: 95-109.

Chapuis MP, Estoup A (2007). Microsatellite null alleles and estimation of population differentiation. Molecular biology and evolution 24: 62131. - doi: 10.1093/molbev/msl191

Concord C, Gurevitch J, Fady B (2012). Largescale longitudinal gradients of genetic diversity: a meta-analysis across six phyla in the Mediterranean basin. Ecology and Evolution 10: 2595-2609.
Dai Q, Fu JZ (2011). When central populations exhibit more genetic diversity than peripheral populations: a simulation study. Chinese Science Bulletin 24: 2531-2540. - doi: 10.1007/s1143 4-011-4605-x

Eckert CG, Samis KE, Lougheed SC (2008). Genetic variation across species' geographical ranges: the central-marginal hypothesis and beyond. Molecular Ecology 17: 1170-1188. - doi: 10.1111/j.1365-294X.2007.03659.x

Fady B, Aravanopoulos FA, Alizoti P, Mátyás C, Von Wühlisch $G$, Westergren $M$, Belletti $P$, Cvjetkovic B, Ducci F, Huber $G$, Kelleher CT, Khaldi A, Kharrat MBD, Kraigher $\mathrm{H}$, Kramer $\mathrm{K}$, Mühlethaler U, Peric S, Perry A, Rousi M, Sbay H, Stojnic S, Tijardovic M, Tsvetkov I, Verela MC, Vendramin GG, Zlatanov T (2016). Evolutionbased approach needed for the conservation and silviculture of peripheral forest tree populations. Forest Ecology and Management 375: 66-75. - doi: 10.1016/j.foreco.2016.05.015 Falush D, Stephens M, Pritchard JK (2003). Inference of population structure using multilocus genotype data: linked loci and correlated allele frequencies. Genetics 164: 567-587. [online] URL: http://www.genetics.org/content/164/4/15 67.short

Fazekas AJ, Yeh FC (2001). Random amplified polymorphic DNA diversity of marginal and central populations in Pinus contorta subsp. latifolia. Genome 44: 13-22. - doi: 10.1139/goo-082 Gapare WJ, Aitken SN (2005). Genetic diversity of core and peripheral Sitka spruce (Picea sitchensis (Bong.) Carr) populations: implications for conservation of widespread species. Biological Conservation 123: 113-123. - doi: 10.1016/j.bio con.2004.11.002

Hardy OJ, Vekemans X (2002). SpaGeDi: a versatile computer program to analyse spatial genetic structure at the individual or population levels. Molecular Ecology 2: 618-620. - doi: 10.1046/j.1471-8286.2002.00305.x

Holzer K (1985). Die Bedeutung der Genetik für den Hochlagenwaldbau [The meaning of genetics for the mountain forests silviculture]. In: Proceedings of the $3^{\text {rd }}$ IUFRO Workshop P.1:07oo "Establishment and tending of subalpine forest: research and management" (Turner $\mathrm{H}$, Tranquillini W eds). Berichte Eidgenossiche, Berlin, Germany, pp. 225-232. [in German]

Hubisz MJ, Falush D, Stephens M, Pritchard JK (2009). Inferring weak population structure with the assistance of sample group information. Molecular Ecology Resources 9: 1322-1332. - doi: 10.1111/j.1755-0998.2009.02591.x

Konnert M, Maurer W (1995). Isozymic Investigations on Norway Spruce (Picea abies (L.) Karst.) and European Silver Fir (Abies alba Mill.). A practical guide to separation methods and zymogram evaluation. Bayerische Landesanstalt für Forstliche Saat und Pflanzenzucht, Teisendorf, Germany, pp. 79.

Kopelman NM, Mayzel J, Jakobsson M, Rosenberg NA, Mayrose I (2015). Clumpak: a program for identifying clustering modes and packaging population structure inferences across K. Molecular Ecology Resources 15: 1179-1191. - doi: 10.1111/1755-0998

Langercrantz U, Ryman N (1990). Genetic structure of Norway spruce (Picea abies): concordance of morfological and allozymic variation. 
Evolution 44:38-53.

Mayr E (1963). Animal species and evolution. Harvard University Press, Cambridge, Massachusetts, USA, pp. 797.

Meloni M, Perini D, Binelli G (2007). The distribution of genetic variation in Norway spruce (Picea abies Karst.) populations in the western Alps. Journal of Biogeography 34 6: 929-938. doi: 10.1111/j.1365-2699.2006.01668.x

Mosca E, Eckert AJ, Di Pierro EA, Rocchini D, La Porta N, Belletti P, Neale DB (2012). The geographical and environmental determinants of genetic diversity for four alpine conifers of the European Alps. Molecular Ecology 21: 55305545. - doi: 10.1111/mec.12043

Mosca E, Gonzalez-Martinez SC, Neale DB (2014). Environmental versus geographical determinants of genetic structure in two subalpine conifers. New Phytology 201: 180-192. doi: 10.1111/nph.12476

Müller-Starck G (1995). Survey of genetic variation as inferred from enzyme gene markers. In: "Genetic variation in European populations of forest trees" (Müller-Starck G, Ziehe M eds). JD Sauerländers Verlag, Frankfurt am Main, Germany, pp. 20-37.

Ohsawa T, Ide $Y$ (2008). Global patterns of genetic variation in plant species along vertical and horizontal gradients on mountains. Global Ecology and Biogeography 17: 152-163. - doi: 10.1111/j.1466-8238.2007.00357.x

Pandey M, Rajora OP (2012). Genetic diversity and differentiation of core vs. peripheral populations of eastern white cedar, Thuja occidentalis (Cupressaceae). American Journal of Botany 99: 690-699. - doi: 10.3732/ajb.1100116

Pfeiffer A, Olivieri AM, Morgante M (1997). Identification and characterization of microsatellites in Norway spruce (Picea abies K.). Genome 40: 411-419. - doi: 10.1139/g97-055

Pritchard JK, Stephens M, Donnelly P (2000). Inference of population structure using multilocus genotype data. Genetics 155: 945-959. [online] URL: http://www.genetics.org/conten $\mathrm{t} / 155 / 2 / 945$

R CoreTeam (2016). R: a language and environment for statistical computing. Vienna, Austria. [online] URL: http://www.r-project.org

Rajora OP, DeVerno L, Mosseler A, Innes DJ (1998). Genetic diversity and population structure of disjunct Newfoundland and central Ontario populations of eastern white pine (Pinus strobus). Canadian Journal of Botany 76 :
500-508. - doi: 10.1139/b98-021

Rajora OP, Rahman MH, Dayanandan S, Mosseler A (2001). Isolation, characterization, inheritance and linkage of microsatellite DNA markers in white spruce (Picea glauca) and their usefulness in other spruce species. Molecular and General Genetics 264: 871-882. - doi: 10.10 $07 / 5004380000377$

Rhodes MJC (1977). The extraction and purification of enzymes from plant tissues. Proceedings of the Biochemical Society 14: 254-248.

Rousset F (2008). Genepop'007: a complete reimplementation of the genepop software for Windows and Linux. Molecular Ecology Resources 8: 103-106. - doi: 10.1111/j.1471-8286.200 7.01931.x

Sakai A, Matusi K, Kabeya D, Sakai S (2003). Altitudinal variation in lifetime growth trajectory and reproductive schedule of a sub-alpine conifer, Abies mariesii. Evolutionary Ecology Research 5: 671-689. [online] URL: http://www. evolutionary-ecology.com/abstracts/v05/1386. html

Schuster R, Oberhuber W (2013). Age-dependent climate-growth relationships and regeneration of Picea abies in a drought-prone mixed coniferous forest in the Alps. Canadian Journal of Forest Research 43: 609-618. - doi: 10.1139/cjfr2012-0426

Scotti I, Magni F, Fink R, Powell W, Binelli G, Hedley PE (2000). Microsatellite repeats are not randomly distributed within Norway spruce (Picea abies K.) expressed sequences. Genome 43: 41-46. - doi: 10.1139/g99-095

Scotti I, Paglia GP, Magni F, Morgante M (2002). Efficient development of dinucleotide microsatellite markers in Norway spruce (Picea abies Karst.) through dot-blot selection. Theoretical and Applied Genetics 104: 1035-1041. - doi: 10.10 07/s00122-001-0843-7

Scotti I, Paglia GP, Magni F, Morgante M (2006). Population genetics of Norway spruce (Picea abies Karst.) at regional scale: sensitivity of different microsatellite motif classes in detecting differentiation. Annals of Forest Science 63: 485-491. - doi: 10.1051/forest:2006029

Skrøppa T (2003). EUFORGEN Technical Guidelines for genetic conservation and use for Norway spruce (Picea abies). International Plant Genetic Resources Institute, Rome, Italy, pp. 6. [online] URL: http://books.google.com/books? id=hrNIgKNYZEcC

Sperisen C, Büchler U, Gugerli F, Mátyás G, Gebu- rek T (2001). Tandem repeats in plant mitochondrial genomes: application to the analysis of population differentiation in the conifer Norway spruce. Molecular Ecology 10: 257-263. doi: 10.1046/j.1365-294X.2001.01180.x

Tollefsrud MM, Kissling R, Gugerli F, Johnsen O, Skrøppa T, Cheddadi R, Van Der Knaap WO, Lataaowa M, Terhürne-Berson R, Litt T, Geburek $\mathrm{T}$, Brochmann C, Sperisen C (2008). Genetic consequences of glacial survival and postglacial colonization in Norway spruce: combined analysis of mitochondrial DNA and fossil pollen. Molecular Ecology 17: 4134-4150. - doi: 10.1111/j. 1365-294X.2008.03893.X

Vendramin GG, Anzidei M, Madaghiele A, Sperisen C, Bucci G (1999). Chloroplast microsatellite analysis reveals the presence of population subdivision in Norway spruce (Picea abies K.). Genome 42: 1-11. - doi: 10.1139/g98-101 Westergren M (2010). Development and practical use of molecular databases in forestry. PhD thesis, Ljubljana, Slovenia, pp. 121.

Yamamichi M, Innan H (2012). Estimating the migration rate from genetic variation data. Heredity 108: 362-363. - doi: 10.1038/hdy.2011.83

Yang A, Dick CW, Yao X, Huang H (2016). Impacts of biogeographic history and marginal population genetics on species range limits: a case study of Liriodendron chinense. Scientific Reports 6: 25632. - doi: 10.1038/srep25632

\section{Supplementary Material}

Fig. S1 - Geographic location of the sampled populations in Slovenia.

Fig. S2 - The Norway spruce population of Smrekova Draga (SD), Slovenia, located along an inverted vegetation gradient occurring in a Karst sinkhole.

Tab. S1 - Pairwise $F_{S T}$ values and p-values for genotypic differentiation among Norway spruce populations based on 13 polymorphic isoenzyme loci.

Tab. S2 - Pairwise $F_{S T}$ values and p-values for genotypic differentiation among Norway spruce populations based on six SSR loci.

Link: Westergren_2444@supploo1.pdf 